derson), with $A$. cinereus and $A$. vexans. Comparing this with $A$. triseriatus from New Jersey and New York, I thought it distinct, but Dr. Dyar doubts whether it is worth naming as a race. Dr. Dyar observes, however, that in Montana also the triseriatus has the silvery lateral areas of mesonotum enlarged, while in Texas and Maryland they are narrow (typical triseriatus), and in Florida they are still more reduced. That is to say, the silvery areas are most developed in the arid west, and most reduced in the humid south.

(17) Aedes vexans Meigen. Very common at lower levels, as along the eastern foothills and adjacent plains. Boulder, Camp Baldwin, Denver, Boone, Grand Junction, Rifle Range near Golden, Grand River 13 miles above Glenwood Springs. It is a species of the Transition Zone with us, and is not found in the high mountains. In Wyoming, it was found at Basin, Box Elder Creek, Shell Creek and near Ten Sleep, being evidently as abundant as in Colorado.

We also have a series of specimens of Aedes with black tarsi, which may represent two or three additional species; but as we have only females, and these mostly in bad condition, nothing definite can be said about them.

I am indebted to Mr. F. Knab for assistance, but also and especially to Dr. H. G. Dyar, who has sent me many named specimens, and has examined all my puzzling forms. Had it not been for his kind assistance and advice, I could not have ventured to write this paper at the present time. ${ }^{1}$

Adjournment.

\title{
SECTION ON APICULTURE
}

[The following is all of the proceedings received by the editor]

\section{IMPORTANT FACTORS IN THE SPREAD AND CONTROL OF AMERICAN FOULBROOD}

\author{
By E. D BaLL.
}

When the apiary inspection work of Wisconsin was recently placed in the writer's charge, a hasty survey was made of the existing situation in the state with reference to the occurrence of foulbrood and the method employed in inspection.

The situation was found to be serious and the inspection methods used totally inadequate under the conditions existing. On extending the survey to other states somewhat similar conditions were found to exist and often similar methods of inspection were in vogue.

\footnotetext{
1 Since the above was written, Prof. C. P. Gillette has very kindly loaned the Culicid collection of the Colorado Agricultural College. This will be reported on at a later date.
} 
From Inspector France's last biennial report we find that he visited 34 places and found foulbrood in 21 of them. If a line is drawn across the map of Wisconsin through Appleton and Eau Claire, thus separating it into northern and southern sections, it will be noted from his report that foulbrood was found in every county in which inspections were made south of that line, excepting three, and only a single place was visited in each one of these three counties. What would have been found if further inspection had been carried on can best be suggested by a glance at the maps showing the areas inspected this season.

North of the line mentioned 6 counties were visited and no foulbrood was found. This does not mean that foulbrood does not exist north of the line, as we have a number of records showing its presence in that region, but it probably indicates that there is far less of it in the northern district than in the southern.

Inspector Kindig in Bulletin 55 reports similar conditions in Michigan and the same difference between the northern and southern parts of the state. Inspector Rea of Pennsylvania in his latest publication reports conditions in that state much better than the above but notes some localities with similar conditions.

As a result of the survey of conditions it was decided that the "area clean-up" method of inspection was the only one that promised to cope with the existing situation, and so the work of the present season was organized along that line. The funds being limited, only three areas were undertaken. Two of these were chosen because active coöperation and support were assured from local associations, and the other to protect the University Experimental Apiary from contagion.

Owing to war calls and bad weather, less work was done than was planned and only parts of each area were covered. As far as the work went, however, every place where bees were kept or where they had been kept at any previous time was inspected. The old hives, frames, etc., in the honey houses or lying around outside were carefully gone over-every living colony was opened and at least four frames from the center of the brood chamber examined, even where no disease was found. Where disease was found in an apiary every frame was examined unless disease was found sooner. This method requires much work and care but the results obtained when charted and compared with previous knowledge were so strikingly different that there was no comparison-or rather that there was a very definite comparison possible.

The following table shows 161 apiaries inspected in 1917 of which 79 or one half of them had foulbrood. This is to be compared with 33 
Tabus I-Rusults of the Season's Worx in tall Cheakup Armas

\begin{tabular}{|c|c|c|c|c|c|c|c|}
\hline \multirow{2}{*}{ Ares No. } & \multicolumn{5}{|c|}{ Apiaries Exsmined } & \multicolumn{2}{|c|}{ Colonies Ingpected } \\
\hline & Total & American & Europesn & Total Diseased & Free & Total & Diseased \\
\hline $\begin{array}{l}1 \\
2 \\
3\end{array}$ & $\begin{array}{l}67 \\
76 \\
18\end{array}$ & $\begin{array}{l}21 \\
28 \\
10\end{array}$ & $\frac{24}{-}$ & $\begin{array}{l}41 \\
28 \\
10\end{array}$ & $\begin{array}{r}26 \\
48 \\
8\end{array}$ & $\begin{array}{r}2,327 \\
1,811 \\
385\end{array}$ & $\begin{array}{r}357 \\
\mathbf{3 1 7} \\
78\end{array}$ \\
\hline Total & 161 & 59 & 24 & 79 & 82 & 4,523 & 752 \\
\hline
\end{tabular}

diseased apiaries found in the whole state in the previous two years of inspection service and only 7 of these in the three counties of which the three cleanup areas covered about one fourth. One fourth of 7 would be an average of 2 for the entire cleanup area but that would not be a fair basis as each cleanup was started from one of the previous cases, so this number should be doubled. But 4 diseased apiaries known where there proved to be 79 shows how really inefficient the old method was and how hopeless the expectation of ever cleaning up any bad area, such as these proved to be, by that method.

It would be foolish to say or to expect that these areas are "cleaned up"-they are not-but the actual condition is now known. Every owner knows his problem and has the knowledge necessary to success; many are already clean, others are on the watch and the reinspection will be comparatively easy in most cases. All this is, however, preliminary to the real object of the present paper.

In the inspection work one is frequently met by the statement that it is of no value to clean up foulbrood in the apiaries as long as the bee-trees cannot be inspected, as the disease will be redistributed over the area from this source. As bee-trees abound in a very large part of the honey-producing section of the state this seemed to be a problem worthy of careful consideration and investigation.

The writer was fortunate enough to be in the field while all the work was carried on in one part of area number 2 , and tried to ascertain the source of each case of American foulbrood found in this district. The results were so striking and so at variance with the common belief as to the general means of spread of this disease that they have been plotted in Figure 1.

We see from the chart that the primary infection occurred along the Wisconsin River. This infection is apparently of long standing as most of the apiaries in the immediate neighborhood have been entirely destroyed for some years past. Mr. S.'s case is typical. He purchased bees from Mr. A. many years ago. From 112 swarms at one time his apiary dwindled down until not a single swarm was left alive. Mr. S. lives beside the only bridge across the river for many miles 
and a sign on this bridge offering for sale the hives, frames and comb distributed this material over a wide area on both sides of the river. Not all of this area has been worked over but every infection with the exception of one (the origin of which is not known) in the region tribu-

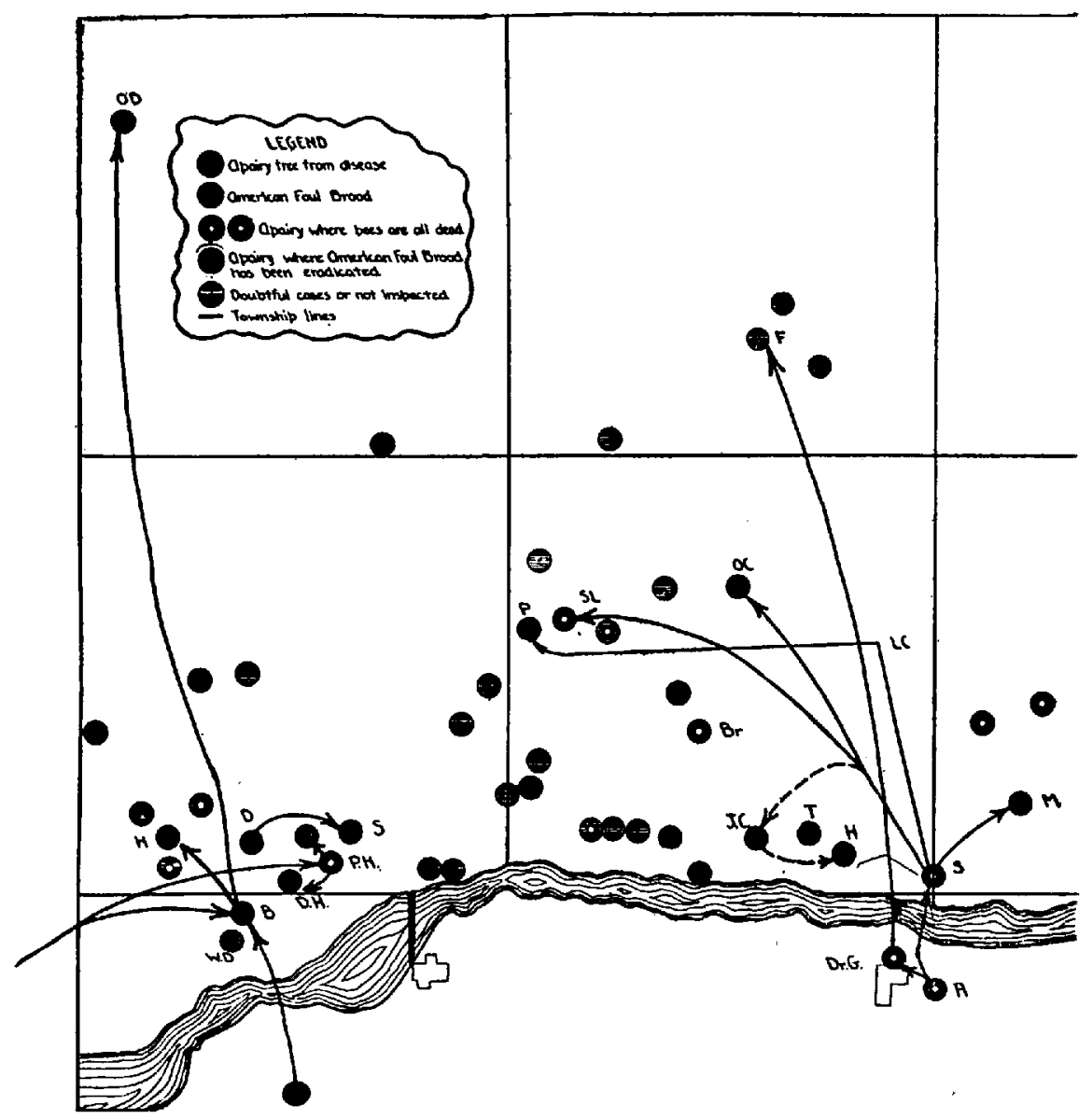

Fig. 9. A part of Area No. 2 showing the method of distribution of American foulbrood in this region.

tary to this bridge can be traced directly or indirectly back to this spot and to this method of distribution.

Two apiaries within a mile of each other are particularly illuminating in this respect. Mr. Sl. purchased a few empty hives from Mr. $S$. a number of years ago and placed them in a then prosperous apiary. Three years ago the last swarm of the apiary died and the entire out- 
fit is now stored in a honey house. Mr. P., within a mile of this apiary on the same ridge, with bees covering the same pasturage, developed a prosperous apiary along side of this, apparently without infection until two years ago when the two remaining swarms of an apiary at some distance (L.C.) were purchased. This apiary had previously bought material from the original source at the bridge. When examined this year these two swarms were badly diseased and everything else in the apiary appeared to be recently infected. Mr. F., owner of a prosperous apiary in another section, bought two swarms from across the river and later discovered that they had foulbrood. He then destroyed them. Still later he found five or six more cases in his yards and destroyed these. His apiaries are now entirely free from disease as is the community.

Just below the next bridge is another badly infected area. Here the origin is somewhat obscure as there may have been two sources. Mr. B. and Mr. P.H. bought bees from another section further down the river several years ago. Mr. B. later bought a single hive from across the river. Soon after the first purchase their bees began to dwindle until Mr. P.H. lost every colony in the apiary where these bees were placed, while Mr. B. had only two left in his.

Five other apiaries in this section were found infected. $\mathrm{Mr}$. B. sold to Mr. O.D., 12 miles distant, who has not been inspected as yet.

Of these five infections three are traceable directly to the two primary ones. Mr. G.'s case is instructive- he bought a few hives from his relative, Mr. D., and they were found badly infected as were $\mathrm{Mr}$. D.'s, while the remainder of Mr. G.'s apiary was only just beginning to show the disease. Yet Mr. G.'s bees had been within a mile of Mr. P.H.'s during the time they died out while Mr. W.D.'s bees were even closer to Mr. B. and remained free from disease.

Out of 20 cases of American foulbrood in this area 15 are apparently definitely known to have been transmitted by the movement of hives and comb, while of the other 5 little information is available. In a number of cases the owners are related and would give little information in regard to possible sources, trying to magnify the importance of the bee-trees and minimize other possible sources. This investigation will be extended to the limits of this area and continued in other areas where the disease exists as they are surveyed, but if the findings of this area are borne out in other situations it will indicate that the most important method of preventing the spread of this disease is a strict quarantine of all infected material and the wide and persistent publicity of the fact that second-hand supplies should never be purchased except from recently inspected premises. Along with this should of course go the cleaning up and eradication of the disease in these areas, 
but that work can go on with much more hope and encouragement if the "bogy" of the diseased bee-tree and the wide transmission of this disease by infected honey can be first eliminated from the minds of the people in country districts and in their place substituted a hope and expectation of freedom from the disease as a result of the "area clean-up" method of treatment.

[Papers read by Title]

\section{AN EMERGENCE RESPONSE OF TRICHOGRAMMA MINUTUM RILEY TO LIGHT'}

\section{By George N. WolcotT}

While temporarily employed by the U. S. Bureau of Entomology from June to August, 1917, to work on sugar-cane insects in the Rio Grande Valley, Texas, the writer collected large numbers of egg clusters of the sugar-cane moth stalk borer, Diatrcea saccharalis Fabr. After trying various localities in the valley where sugar-cane was grown, Harlingen, Texas, was selected for continuous work, as in two fields there about a mile north of the railroad station, Diatroxa was very abundant. In all, 1,506 clusters were collected from these two fields, and of these 944 , or 62.6 per cent, were parasitized by the hymenopteron, Trichogramma minutum.

The individual Diatrca egg is oval and flattened, lenticular in crosssection, and these plate-like eggs are deposited in single, double or triple (or irregularly four, five, and sometimes even six) rows, overlapping like shingles or slates on a roof. The following table gives the number of eggs in the masses, and the frequency with which different numbers occurred:

$\begin{array}{cccccc}\text { Number } & \text { Frequency } & \text { Number } & \text { Frequency } & \text { Number } & \text { Frequency } \\ 3 & 2 & 18 & 66 & 33 & 19 \\ .4 & 1 & 19 & 76 & 34 & 14 \\ 5 & 1 & 20 & 50 & 35 & 16 \\ 6 & 7 & 21 & 56 & 36 & 11 \\ 7 & 19 & 22 & 55 & 37 & 10 \\ 8 & 20 & 23 & 53 & 38 & 11 \\ 9 & 35 & 24 & 44 & 39 & 5 \\ 10 & 38 & 25 & 40 & 40 & 5 \\ 11 & 47 & 26 & 30 & 41 & 11 \\ 12 & 48 & 27 & 36 & 42 & 4 \\ 13 & 50 & 28 & 27 & 43 & 6 \\ 14 & 49 & 29 & 17 & 44 & 2 \\ 15 & 64 & 30 & 21 & 45 & 6 \\ 16 & 63 & 31 & 11 & 46 & 5 \\ 17 & 66 & 32 & 27 & 47 & 7\end{array}$

1 Published by permission of the Chief of the Bureau of Entomology. 